\title{
Gender Dysphoria Treatment: A Critical Discussion of Medical and Psychotherapeutic Approaches in Adults and Young People
}

\author{
Marios Dimitrios Chatzinikolaou ${ }^{1, *}$ \\ ${ }^{1}$ Department of Psychology, University of Derby, United Kingdom \\ *Corresponding author
}

\begin{abstract}
Gender Dysphoria focuses on the psychological state at which individuals experience low levels of perceived satisfaction regarding their primary and secondary physiological traits, their biological gender, and their assigned societal gender roles. This condition primarily requires multidisciplinary and personalised treatment. Scientific evidence suggests that utilisation of gonadotropin-releasing hormone analogues, puberty blockers, and genderaffirming surgery may reduce distress, enhance mental health and quality of life, while diminishing Gender Dysphoria. However, some researchers contend that medical procedures pose adverse limitations since they may result in complications, feelings of frustration, and supplementary procedures undergone for aesthetic purposes. Moreover, individuals' age of readiness to pursue medical interventions and deal with additional issues such as post-surgery fertility and regret also need to be addressed. Conversely, psychotherapy and counselling intend to assist such individuals in accomplishing long-term relief relating to their gender identity, developing their interpersonal skills, and confronting Gender Dysphoria comorbidity. Yet, many psychotherapeutic schemes insufficiently address crucial facets of Gender Dysphoria, namely societal discrimination stemming from subsequent stigmatization, promotion of resilience among this highly marginalised population against unprecedented tribulation, and body dissatisfaction, thus not providing a complete relief of gender dysphoric feelings. Therefore, it is essential to appropriately address psychosocial functionality enhancement, integrate novel treatment propositions into a holistic therapeutic plan, and further develop/validate Gender Dysphoria metrics that can be universally accepted in order to prevent pathologisation of these individuals. It is also recommended that further qualitative data, needs assessments, and empirical studies be gathered, while carefully abiding by the necessary ethical considerations.
\end{abstract}

Keywords: clinical psychology, depathologisation, multidisciplinary care, psychopathology, quality of life

\section{Gender Dysphoria Re-Evaluation in the DSM-V}

The re-evaluated specification of Gender Dysphoria (GD) (previously identified as Gender Identity Disorder in the DSM-IV) concentrates on the psychological state at which individuals experience low levels of perceived satisfaction regarding their birth-assigned gender along with their gender role, as outlined by societal norms, for a minimum timeframe of six months (American Psychiatric Association, 2013). Put differently, this condition leads individuals to 
experience distinctive levels of distress stemming from discomfort/incongruence with primary/secondary traits and their biological gender, in conjunction with their assigned roles in society (Bizic et al., 2018). On this account, sex reassignment through hormonal replacement or gender affirmation surgery is regularly requested by GD individuals (CohenKettenis \& Pfäfflin, 2010), and those encountering gender incongruence jeopardise developing psychological distress and social/occupational impairment of functionality which is linked to suicidality (Wang, 2019). Hence, the imperative need to explore the utility of psychological treatments should not be disregarded by clinicians and investigators.

\subsection{Treatment Aims}

Medical professionals globally resort to the World Professional Association for Transgender Health's (WPATH) (2011) and the Endocrine Society's published recommendations for the care of transgender patients, which ought to be both high-quality and evidence-based. The alleviation of distress and affirmation of patients' experienced gender identity is the ultimate aim of all treatment configurations (WPATH, 2011; Hembree, 2011). GD individuals are confronted with two primary options; (a) they can opt for socially transitioning into their affirmed gender via non-invasive directions (utilising opposite sex's salutations, external appearance adjustments, adopting their desired genders' social roles, and reversible hormonal therapies), or (b) they can proceed to more invasive pathways, encompassing non-reversible hormonal and/or surgical treatments (Bizic et al., 2018). However, medical professionals should take into account that, principally, GD treatments should be multidisciplinary and personalized, including a variety of treatment modalities, namely, cross-sex hormonal therapy, social gender transition, gender-affirming surgery, ancillary procedures and services, and psychotherapy (Hadj-Moussa, Ohn \& Kuzon, 2018).

\section{Hormonal Therapy}

Bioethical considerations have risen regarding the arbitrariness of previous applications of hormonal therapy and surgical interventions on treating GD, owing to the amount of significant negative consequences projected to individuals (Coleman et al., 2012). Recent revisions prioritise the obtainment/documentation of patients' informed consent in their medical record afore initiating hormonal/surgical interventions, along with the suitability criterion by WPATH regarding an individual's age, determined by local laws and regulations (Wilczynski \& Emanuele, 2014). Hence, contemporary hormonal therapy [e.g., Gonadotropin-Releasing Hormone (GnRH), puberty blockers, cross-sex hormonal therapy] as prescribed by endocrinologists for a minimum of one year is a prerequisite for individuals wishing to undergo gender-affirming surgery (GAS).

\subsection{Gonadotropin Releasing Hormone and Puberty Blockers}

Certain evidence suggests that utilisation of GnRH analogues and puberty blockers is an effective/beneficial technique of reducing distress, diminishing GD, and enhancing mental health, along with general functioning, especially in transgender youth (De Vries et al., 2011; Zucker, 2019), which is considered a highly marginalized population. To that end, suppressing secondary non-congruent sexual features and domestic puberty provides time for further exploration of individuals' gender and reflection upon their identity options in 


\section{2nd World Conference on Teaching and Education}

counseling/psychotherapy, due to the early transition onset (Costa et al., 2015). This gradually facilitates the transition in terms of the desired social identity/role and can improve psychological well-being.

Although the reversibility of these treatments is considered one of their paramount assets, Viner et al. (2005) contends that they generate physically harmful consequences, resulting in psychological distress. Still, the benefits of such protocols have been affirmed by de Vries et al.'s (2014) research, without, however, providing sufficient evidence on their long-term effects and without including separate options like psychosocial approaches to treatment. Nevertheless, in numerous studies, methodological issues emerge (e.g., absence of control groups), acting as treatment efficiency barriers to evaluation (Cohen \& Barnes, 2019). Further major counterarguments on this treatment effectiveness for children/adolescents allege that puberty itself is a transitioning period that could help individuals get accustomed to and decide to adhere to the assigned gender, as GD may not persist throughout adolescence (Hembree et al., 2017). Regardless, an emerging trend involves initiation of treatment as early as mid-adolescence, alternatively to adulthood. Not surprisingly, this draws further concerns regarding puberty suppression's relative usefulness, illustrating the possibility of partially predisposing young individuals to compulsorily follow medical/surgical transition paths (Butler, Wren, \& Carmichael, 2019).

Notwithstanding the foregoing, cross-sex hormonal therapy's impact on GD transgender youth has been investigated by only a small proportion of research. Jarin et al.'s (2017) retrospective study showed a minor impact of hormonal treatment on 116 adolescents of ages 14-25 years, reporting low level changes in physiological parameters ${ }^{1}$, without any known safety implications for at least two years following its administration (Olson-Kennedy, Okonta, Clark, \& Belzer, 2018; Jarin et al., 2017). Henceforth, the plausibility of cross-sex hormonal therapy initiation/usefulness prior to the age of 16 remains controversial. Likewise, although there is some recognition of convincing justifications for introducing hormonal therapy prior to the age of 16 , only a limited quantity of publications explores such treatment experiences before 14 years of age. Thus, issues arise since an individual's readiness to pursue medical interventions might not be perpetually accurately reflected by their age (Viner, 2005). Conversely, hormonal treatment in GD transgender adults has been deemed highly efficient and ultimately safe by current reviews (Hadj-Moussa et al., 2018). However, emphasis has been placed towards concerning corporeal side-effects ${ }^{2}$ in transgender women (Asscheman et al., 2014) and, respectively, particular caution over undesirable physical outcomes $^{3}$ of testosterone treatment in transgender men was raised by Hembree et al. (2009). For that reason, most authors suggest necessary follow-up to detect potential complications, but overall, they demonstrated ample safety of this treatment (Colebunders et al., 2017). Nevertheless, what should be conclusively considered is that the long-term effects of such hormonal treatments remain unknown and more studies need to follow-up to that direction.

\footnotetext{
${ }^{1}$ Blood count levels, levels of testosterone, decreased bone mass, and body mass index.

${ }^{2}$ Venous thromboembolism and estrogen induced hyper-coagulability.

${ }^{3}$ Polycythemia vera and dyslipidemia.
} 


\title{
2nd World Conference on Teaching and Education
}

\author{
19-21 February, 2021
}

Vienna, AUSTRIA

\section{Gender Affirmation Surgery}

In cases of subsequent persistence of GD feelings for adolescents undergoing hormonal medication that either suppresses or delays puberty, proceeding to GAS, involving all surgical procedures performed when pursuing precise similarity to the affirmed gender ${ }^{4}$, serves as a more appropriate solution (Cohen-Kettenis et al., 2011; Zucker et al., 2011). GAS has been recently displayed to considerably improve individuals' quality of life (QoL), self-esteem and body image perception, while reducing GD feelings (Agarwal et al., 2018). Still, it should be noted that facial feminisation surgery can be qualified as a rewarding yet challenging procedure for both the surgeon and the individual undergoing it, by means of requiring a multidisciplinary approach to care (Spiegel, 2008; Ainsworth \& Spiegel, 2010). In most cases, individuals subjected to surgery (e.g., chest reconstruction) exhibit an increase in overall QoL, with transgender men reporting lower satisfaction levels than transgender women who display ameliorated social relations, self-esteem, and body-related satisfaction. Remarkably, mastectomy is stationed among the most effective surgical procedures, exclusively having significant outcomes in all factors influencing QoL in relevant research (Passos, Teixeira \& Almeida-Santos, 2019). On top of that, indications of reduction in additional mental health treatment for individuals decided to undergo GAS further support the advantageous nature of such strategies (Bränström \& Pachankis, 2019). But the real question still revolves around the scope of whether such treatment plans are a genuinely beneficial pathway for GD individuals to follow.

Despite being a fairly efficient treatment approach, surgical procedures pose profuse limitations, since they might result in complications, feelings of frustration, and additional procedures undergone for aesthetic purposes (Passos et al., 2019). Besides, satisfaction responses seem to be lower compared to control groups in studies by Kuhn et al. (2009). This could, however, be attributed to pre-existing psychological issues, thus the deduction that GAS was the precursor of low satisfaction levels would be imprecise. Likewise, Da Silva and colleagues (2016) conducted a study in Brazil whereby aspects of the individuals' daily life deteriorated following surgery, which is further confirmed by Castellano et al. (2015) who maintained that the complexity of the procedure per se (e.g., phalloplasty) poses obstacles to the individuals' well-being and perceived life satisfaction.

Ethical issues equally inevitably occur, as the nature, etiology, and definition of GD are rather complex/inconclusive, and thus cannot contribute to the best fit for the individual seeking treatment (Bizic et al., 2018). Some challenges include the treatment of underage individuals, post-GAS fertility, and possible post-surgery regret. Therefore, the underlying principles of ethical decision-making ${ }^{5}$ in GAS should always be pre-considered (Levine, 2017) since such ethics-related concerns can generate multiple questions regarding the complete efficiency of surgical treatments. Consequently, the high-quality supportive evidence regarding their usefulness needs to be enriched (Hruz, 2019).

\footnotetext{
${ }^{4}$ GAS can be further sub-categorized into genital (phalloplasty, metoidioplasty, oophorectomy, vaginoplasty, and bilateral orchiectomy) and non-genital surgeries (chest and facial surgery).

${ }^{5}$ Informed consent, beneficence, nonmaleficence, and autonomy.
} 


\subsection{Substitute Gender-Affirmative Procedures}

Other gender-affirmative interventions frequently followed by GD transgender people are hair removal interventions, through laser hair removal and electrolysis (James et al., 2016; Sabra, Fang, \& Kundu, 2018), and they posteriorly exhibit fewer symptoms of depression, anxiety, and higher self-satisfaction levels (Bradford, Rider, \& Spencer, 2019). Noteworthily, however, individuals seeking such interventional directions aim at improving their psychosocial functioning as well, apart from merely satisfying their aesthetic desires (Dubov \& Fraenkel, 2018). Judging from the abovementioned indications, it is recommended that medical professionals should also direct their attention towards individuals' psychosocial functionality enhancement, as it seems that biomedical treatment options fail to simultaneously address GD individuals' psychosocial/psychological vulnerability, which is especially evident in previous research (Bechard et al., 2016). The implementation of such fundamental aspects into biomedical treatment models may result in more robust, multidisciplinary interventions that are holistically efficient for GD individuals. The paradigm of emphasising more on biomedical and only partially on psychosocial perspectives should be revised and shifted towards achieving better efficiency of treatment options (Murshak, 2017).

\section{The Role of Mental Health Professionals in Multidisciplinary Care}

The intensified psychological distress, dysphoric feelings, and functionality impairment experienced by GD individuals can be attempted to be resolved primarily by Mental Health Professionals (MHPs). MHPs ought to support individuals dealing with GD regarding adversities deriving from interpersonal relationships and behaviour-related issues ${ }^{6}$ (Giovanardi et al., 2018). Directions towards stronger psychotherapeutic standards can be achieved by MHPs' identifying and confronting GD comorbidity, associated with conditions which GD individuals are at a higher risk of developing (e.g., depression, suicidality, substance abuse, anxiety, self-injury, and other harmful indications) (De Vries, 2016; GarcíaVega, Camero, Fernández, \& Villaverde, 2018). By the same token, attention should be placed towards proposing interventions that focus on the macrosocial minority stress experienced by GD individuals (Bockting et al., 2013).

\subsection{Psychotherapeutic Objectives and Approaches in Gender Dysphoria}

Psychotherapy/counseling intends to maximize GD individuals' overall QoL and does not merely focus on achieving a gender transition through invasive methods, assisting them in accomplishing long-term relief relating to their gender identity/expression, developing their interpersonal skills and increasing their resilience in the face of tribulation related to subsequent stigmatisation (Hadj-Moussa et al., 2018; Coleman et al., 2012). In countries following the Standards of Care guidelines (American Psychological Association, 2015), where it is no longer considered a requirement for proceeding to surgery (Budge, 2015), ongoing psychotherapy seems to be yielding positive outcomes for individuals, even resulting in post-surgery satisfaction for those determined to undergo invasive treatments (Berg, 1997; Rehman, 1999).

\footnotetext{
${ }^{6}$ They further act as individuals' advocates regarding the stipulated legalities of pertinent procedures and necessary medical reassurances.
} 


\section{2nd World Conference on Teaching and Education}

Predominantly though, insufficient manipulation of children exhibiting GD may result in psychological distress, manifested in feelings of isolation and suicidal thoughts/attempts (Hasan et al., 2017). To address that, although children constitute a small percentage of GD individuals, the prospect of them continuing to experience dysphoric feelings in adolescence should be considered by MHPs. Therefore, MHPs' main objective should be the provision of gender affirming treatment plans that are compatible to each individual's needs. Treatment plans' degree of efficiency is optimised when MHPs correspondingly support GD individuals through personalising psychotherapeutic approaches and including members of their social support system, thus aiding individuals at identifying their gender related needs/goals, evaluating their available social resources, and eliminating comorbid indications (Wylie et al., 2016; Bockting, 2008). In turn, psychodynamic integrations to psychotherapy have been largely proposed as therapeutic interventions to children experiencing GD (Kaltiala-Heino et al., 2018). Even so, psychotherapy remains inadequate when endeavoring to improve their QoL and psychodynamic incorporations have produced unsatisfactory results regarding their usefulness (Möller, Schreier, Li, \& Romer, 2009), appearing insufficient at providing a complete relief of GD feelings. Their supplementary evaluation to examine their suitability in treating GD is, therewith, essential.

The underlying reason for the partial inefficiency of such treatments can be attributed to two crucial aspects that many psychotherapeutic approaches may not focus on properly addressing; societal discrimination GD individuals are faced with and the promotion of resilience amongst such vulnerable populations (Zeeman, Aranda, Sherriff, \& Cocking, 2017). Since poor resilience and social vulnerability of GD individuals is correlated to intensification of mental and behavioural problems (Burton et al. 2013), the observed importance of psychological adjustment against social discrimination/exclusion (European Union Agency for Fundamental Rights, 2014) stipulates the necessity of robustly integrating resilience into psychotherapeutic approaches, constituting them more effectual. The inadequate evidence regarding the beneficial influence of supportive environments on GD youth specifically (Janssen, Busa, \& Wernick, 2019) may also indicate their poor reinforcement by psychotherapeutic standpoints. Partly overlooking the assertion that perceived social support throughout different contexts is evidently correlated with long-term psychological adjustment (Davey et al., 2014) will doubtfully constitute psychological treatment alignments more holistic. Thereupon, the amount of literature relevant to mental health treatment directly addressing GD has been insufficient and thus inconclusive.

\subsection{Dialectical Behaviour Therapy \& Body Image Therapy}

Research indicates that GD cannot be mitigated by utilising an exclusive approach to psychotherapy/counseling purely (Sloan \& Berke, 2018). In this regard, treating GD directly has been partially investigated by using Dialectical Behaviour Therapy (DBT), where GD individuals are given feedback on the possible effect of invalidation on their emotional regulation abilities, behavioural patterns, and on their sense of self-stability (Sloan \& Berke, 2018; Linehan, 1987). Hence, DBT's applications for handling GD individuals' social oppression/invalidation are useful. By contrast, DBT fails to address the most prominent/primary GD linked issue, body dissatisfaction (Wang, 2019), constituting it incomprehensive to target GD's uninvestigated facets. Thus, the integration of GD antecedents into psychotherapeutic approaches might be of significance. Presently, newly 


\section{2nd World Conference on Teaching and Education}

developed treatment propositions, particularly Body Image Therapy ${ }^{7}$ (Wang, 2019), unswervingly address GD transgender individuals' body distress, establishing high efficiency in alleviating dominant body discomfort associated with GD. Implementing this treatment model into future research/literature is vital for assessing its outcomes and validity for GD populations.

\section{Conclusions and Recommended Directions}

Overall, a complete evaluation of biomedical procedures' results and usefulness remains complicated due to researchers and medical professionals' not identifying their long-term outcomes and relying merely on currently available instruments, which were initially employed to explore different conditions than GD explicitly. Thereof, the development and validation of GD metrics that can be universally accepted is of the utmost importance. Psychological therapies also entail further discussion, as their entire effectiveness remains partially unknown and, as of today, a range of psychological therapies have been incorporated inefficiently at providing a thorough treatment plan for GD. Integrating novel treatment propositions into a holistic plan for reducing GD's uninvestigated aspects should lead to remedies being more efficient for individuals. The conclusion deriving from the aforementioned discussion elements adds to the further complexity of treatments' holistic efficiency; if biomedical and psychological treatment viewpoints are inspecting/targeting only a sequence of symptomatology [as mostly reflected by social issues' medicalization in the Western society (Inch, 2016)], then depathologisation of GD individuals, which is considered a human right, will be constantly imperiled. The reconstruction of treatment plans by medical professionals and practitioners is important to prevent pathologising and psychopathologising individuals with GD. However, the whole purposefulness of treatments is already subjected to issues of the condition's conceptual clarity (Ashley, 2019). Amidst all the uncertainty vis-à-vis a thorough formulation of efficient treatment strategies, future research requires gathering additional qualitative research and empirical studies for appropriately evaluating the relative usefulness of treatments at providing a multidisciplinary/holistic approach to the care of GD individuals, while abiding by the necessary ethical considerations.

\section{Acknowledgment}

This paper is an output of a psychopathology module in the second year of the BSc (Honours) in Applied Psychology at the University of Derby. Therefore, I would like to deeply thank my tutor, Mr. Georgios Thomas, for his invaluable guidance regarding the structural composition of this critical essay.

\section{References}

Agarwal, C. A., Scheefer, M. F., Wright, L. N., Walzer, N. K., \& Rivera, A. (2018). Quality of life improvement after chest wall masculinization in female-to-male transgender patients: A prospective study using the BREAST-Q and Body Uneasiness Test. Journal of Plastic, Reconstructive \& Aesthetic Surgery, 71(5), 651-657. doi:10.1016/j.bjps.2018.01.003

\footnotetext{
${ }^{7}$ A gender-specific variation of the Cognitive Behavior Therapy model for Binge Eating Disorder.
} 


\section{2nd World Conference on Teaching and Education}

\section{9-21 February, 2021}

Vienna, AUSTRIA

Ainsworth, T. A., \& Spiegel, J. H. (2010). Quality of life of individuals with and without facial feminization surgery or gender reassignment surgery. Quality of Life Research, 19(7), 1019-1024. doi:10.1007/s11136-010-9668-7.

American Psychiatric Association. (2013). Diagnostic and statistical manual of mental disorders (DSM-5®). American Psychiatric Pub. doi: 10.1007/978-88-470-5696-1_4

American Psychological Association. (2015). Guidelines for psychological practice with transgender and gender nonconforming people. American Psychologist, 70(9), 832-864.

Ashley, F. (2019). The Misuse of Gender Dysphoria: Toward Greater Conceptual Clarity in Transgender Health. Perspectives on Psychological Science. doi:10.1177/1745691619872987

Asscheman, H., T’Sjoen, G., Lemaire, A., Mas, M., Meriggiola, M. C., Mueller, A., ... Gooren, L. J. (2014). Venous thrombo-embolism as a complication of cross-sex hormone treatment of male-to-female transsexual subjects: a review. Andrologia, 46(7), 791795. doi:10.1111/and.12150

Bauer, G. R., Scheim, A. I., Pyne, J., Travers, R., \& Hammond, R. (2015). Intervenable factors associated with suicide risk in transgender persons: a respondent driven sampling study in Ontario, Canada. BMC Public Health, 15(1). doi:10.1186/s12889-015-1867-2

Bechard, M., VanderLaan, D. P., Wood, H., Wasserman, L., \& Zucker, K. J. (2016). Psychosocial and Psychological Vulnerability in Adolescents with Gender Dysphoria: A "Proof of Principle" Study. Journal of Sex \& Marital Therapy, 43(7), 678688. doi:10.1080/0092623x.2016.1232325

Berg, J. E. A., \& Gustafsson, M. (1997). Long Term Follow up After Sex Reassignment Surgery. Scandinavian Journal of Plastic and Reconstructive Surgery and Hand Surgery, 31(1), 39-45. doi:10.3109/02844319709010503

Bizic, M. R., Jeftovic, M., Pusica, S., Stojanovic, B., Duisin, D., Vujovic, S., ... \& Djordjevic, M. L. (2018). Gender dysphoria: bioethical aspects of medical treatment. BioMed Research International, 2018. doi: 10.1155/2018/9652305

Bockting, W. O. (2008). Psychotherapy and the real-life experience: From gender dichotomy to gender diversity. Sexologies, 17(4), 211-224. doi:10.1016/j.sexol.2008.08.001

Bockting, W. O., Miner, M. H., Swinburne Romine, R. E., Hamilton, A., \& Coleman, E. (2013). Stigma, Mental Health, and Resilience in an Online Sample of the US Transgender Population. American Journal of Public Health, 103(5), 943-951.

doi:10.2105/ajph.2013.301241

Bradford, N. J., Rider, N., \& Spencer, K. G. (2019). Hair removal and psychological wellbeing in transfeminine adults: Associations with gender dysphoria and gender euphoria. Journal of Dermatological Treatment, 1-27. doi:10.1080/09546634.2019.1687823

Bränström, R., \& Pachankis, J. E. (2019). Reduction in mental health treatment utilization among transgender individuals after gender-affirming surgeries: a total population study. American journal of psychiatry. doi: 10.1176/appi.ajp.2019.19010080

Budge, S. L. (2015). Psychotherapists as gatekeepers: An evidence-based case study highlighting the role and process of letter writing for transgender clients. Psychotherapy, 52(3), 287-297. doi:10.1037/pst0000034

Burton, C. M., Marshal, M. P., Chisolm, D. J., Sucato, G. S., \& Friedman, M. S. (2013). Sexual Minority-Related Victimization as a Mediator of Mental Health Disparities in 


\section{2nd World Conference on Teaching and Education}

\section{9-21 February, 2021}

Vienna, AUSTRIA

Sexual Minority Youth: A Longitudinal Analysis. Journal of Youth and Adolescence, 42(3), 394-402. doi:10.1007/s10964-012-9901-5

Butler, G., Wren, B., \& Carmichael, P. (2019). Puberty blocking in gender dysphoria: suitable for all? Archives of Disease in Childhood. doi:10.1136/archdischild-2018-315984

Cardoso da Silva, D., Schwarz, K., Fontanari, A. M. V., Costa, A. B., Massuda, R., Henriques, A. A., ... Lobato, M. I. R. (2016). WHOQOL-100 Before and After Sex Reassignment Surgery in Brazilian Male-to-Female Transsexual Individuals. The Journal of Sexual Medicine, 13(6), 988-993. doi:10.1016/j.jsxm.2016.03.370

Castellano, E., Crespi, C., Dell'Aquila, C., Rosato, R., Catalano, C., Mineccia, V., ... Manieri, C. (2015). Quality of life and hormones after sex reassignment surgery. Journal of Endocrinological Investigation, 38(12), 1373-1381. doi:10.1007/s40618-015-0398-0

Cohen, D., \& Barnes, H. (2019). Gender dysphoria in children: puberty blockers study draws further criticism. BMJ, 366. doi: 10.1136/bmj.15647

Cohen-Kettenis, P. T., \& Pfäfflin, F. (2010). The DSM Diagnostic Criteria for Gender Identity Disorder in Adolescents and Adults. Archives of Sexual Behavior, 39(2), 499513. doi:10.1007/s10508-009-9562-y

Cohen-Kettenis, P. T., Steensma, T. D., \& de Vries, A. L. (2011). Treatment of adolescents with gender dysphoria in the Netherlands. Child and Adolescent Psychiatric Clinics, 20(4), 689-700. doi: 10.1016/j.chc.2011.08.001.

Colebunders, B., Brondeel, S., D’Arpa, S., Hoebeke, P., \& Monstrey, S. (2017). An Update on the Surgical Treatment for Transgender Patients. Sexual Medicine Reviews, 5(1), 103-109. doi:10.1016/j.sxmr.2016.08.001

Coleman, E., Bockting, W., Botzer, M., Cohen-Kettenis, P., DeCuypere, G., Feldman, J., ... $\&$ Monstrey, S. (2012). Standards of care for the health of transsexual, transgender, and gender-nonconforming people, version 7. International journal of transgenderism, 13(4), 165-232. doi: 10.1080/15532739.2011.700873

Costa, R., Dunsford, M., Skagerberg, E., Holt, V., Carmichael, P., \& Colizzi, M. (2015). Psychological Support, Puberty Suppression, and Psychosocial Functioning in Adolescents with Gender Dysphoria. The Journal of Sexual Medicine, 12(11), 22062214. doi:10.1111/jsm.13034

Davey, A., Bouman, W. P., Arcelus, J., \& Meyer, C. (2014). Social Support and Psychological Well- Being in Gender Dysphoria: A Comparison of Patients With Matched Controls. The Journal of Sexual Medicine, 11(12), 2976-2985. doi:10.1111/jsm.12681

De Vries, A. L. C., Steensma, T. D., Doreleijers, T. A. H., \& Cohen- Kettenis, P. T. (2011). Puberty Suppression in Adolescents With Gender Identity Disorder: A Prospective Follow- Up Study. The Journal of Sexual Medicine, 8(8), 2276-2283. doi:10.1111/j.17436109.2010.01943.x

De Vries, A. L., McGuire, J. K., Steensma, T. D., Wagenaar, E. C., Doreleijers, T. A., \& Cohen-Kettenis, P. T. (2014). Young adult psychological outcome after puberty suppression and gender reassignment. Pediatrics, 134(4), 696-704.

De Vries, A. L., Steensma, T. D., Cohen-Kettenis, P. T., VanderLaan, D. P., \& Zucker, K. J. (2016). Poor peer relations predict parent-and self-reported behavioral and emotional problems of adolescents with gender dysphoria: a cross-national, cross-clinic comparative 


\section{2nd World Conference on Teaching and Education}

\section{9-21 February, 2021}

Vienna, AUSTRIA

analysis. European child \& adolescent psychiatry, 25(6), 579-588. doi:10.1007/s00787-0150764-7

Dubov, A., \& Fraenkel, L. (2018). Facial feminization surgery: The ethics of gatekeeping in transgender health. The American Journal of Bioethics, 18(12), 3-9.

doi:10.1080/15265161.2018.1531159

European Union Agency for Fundamental Rights (2014) Being Trans in the European Union: Comparative analysis of EU LGBT survey data. Publications Office of the European Union: Luxembourg.

García-Vega, E., Camero, A., Fernández, M., \& Villaverde, A. (2018) Suicidal ideation and suicide attempts in persons with gender dysphoria. Psicothema, 30(3), 283-289, doi:10.7334/psicothema2017.438

Giovanardi, G., Vitelli, R., Maggiora Vergano, C., Fortunato, A., Chianura, L., Lingiardi, V., \& Speranza, A. M. (2018). Attachment Patterns and Complex Trauma in a Sample of Adults Diagnosed with Gender Dysphoria. Frontiers in Psychology,

9. doi:10.3389/fpsyg.2018.00060

Hadj-Moussa, M., Ohl, D. A., \& Kuzon Jr, W. M. (2018). Evaluation and treatment of gender dysphoria to prepare for gender confirmation surgery. Sexual medicine reviews, 6(4), 607-617. doi: 10.1016/j.sxmr.2018.03.006

Hasan, S., Alviany, Y., Clarissa, C., \& Sudana, S. (2017). High perceived discrimination and no family support increase risk of poor quality of life in gender dysphoria. Universa Medicina, 36(3), 187-196. doi:10.18051/UnivMed.2017.v36.187-196

Hembree, W. C. (2011). Guidelines for Pubertal Suspension and Gender Reassignment for Transgender Adolescents. Child and Adolescent Psychiatric Clinics of North America, 20(4), 725-732. doi:10.1016/j.chc.2011.08.004

Hembree, W. C., Cohen-Kettenis, P. T., Gooren, L., Hannema, S. E., Meyer, W. J., Murad, M. H., ... \& T'Sjoen, G. G. (2017). Endocrine treatment of gender-dysphoric/genderincongruent persons: an endocrine society clinical practice guideline. The Journal of Clinical Endocrinology \& Metabolism, 102(11), 3869-3903. doi: 10.1530/ey.15.6.3

Hembree, W. C., Cohen-Kettenis, P., Delemarre-van de Waal, H. A., Gooren, L. J., Meyer, W. J., Spack, N. P., ... Montori, V. M. (2009). Endocrine Treatment of Transsexual Persons: An Endocrine Society Clinical Practice Guideline. The Journal of Clinical Endocrinology \& Metabolism, 94(9), 3132-3154. doi:10.1210/jc.2009-0345

Hruz, P. W. (2019). Deficiencies in Scientific Evidence for Medical Management of Gender Dysphoria. The Linacre Quarterly. doi:10.1177/0024363919873762

Inch, E. (2016). Changing Minds: The Psycho-Pathologization of Trans People.

International Journal of Mental Health, 45(3), 193-

204. doi:10.1080/00207411.2016.1204822

James, S., Herman, J., Rankin, S., Keisling, M., Mottet, L., \& Anafi, M. A. (2016). The report of the 2015 US transgender survey, National Center for Transgender Equality, Washington, DC.

Janssen, A., Busa, S., \& Wernick, J. (2019). The Complexities of Treatment Planning for Transgender Youth with Co-Occurring Severe Mental Illness: A Literature Review and Case Study. Archives of Sexual Behavior. doi:10.1007/s10508-018-1382-5 


\section{2nd World Conference on Teaching and Education}

\section{9-21 February, 2021}

Vienna, AUSTRIA

Jarin, J., Pine-Twaddell, E., Trotman, G., Stevens, J., Conard, L. A., Tefera, E., \& GomezLobo, V. (2017). Cross-Sex Hormones and Metabolic Parameters in Adolescents With Gender Dysphoria. Pediatrics, 139(5). doi:10.1542/peds.2016-3173

Kaltiala-Heino, R., Bergman, H., Työläjärvi, M., \& Frisen, L. (2018). Gender dysphoria in adolescence: current perspectives. Adolescent Health, Medicine and Therapeutics, 9, 3141. doi:10.2147/ahmt.s135432

Kuhn, A., Bodmer, C., Stadlmayr, W., Kuhn, P., Mueller, M. D., \& Birkhäuser, M. (2009). Quality of life 15 sources after sex reassignment surgery for transsexualism. Fertility and Sterility, 92, 1685-1689. doi: 10.1016/j.fertnstert.2008.08.126.

Legenbauer, T., Schütt-Strömel, S., Hiller, W., \& Vocks, S. (2011). Predictors of improved eating behaviour following body image therapy: A pilot study. European Eating Disorders Review, 19(2), 129-137. doi:10.1002/erv.1017

Levine, S. B. (2017). Ethical Concerns About Emerging Treatment Paradigms for Gender Dysphoria. Journal of Sex \& Marital Therapy, 44(1), 29-

44. doi:10.1080/0092623x.2017.1309482

Linehan, M. M. (1987). Dialectical behavior therapy for borderline personality disorder: Theory and method. Bulletin of the Menninger Clinic, 51(3), 261.

Möller, B., Schreier, H., Li, A., \& Romer, G. (2009). Gender Identity Disorder in Children and Adolescents. Current Problems in Pediatric and Adolescent Health Care, 39(5), 117143. doi:10.1016/j.cppeds.2009.02.001

Möller, B., Schreier, H., Li, A., \& Romer, G. (2009). Gender Identity Disorder in Children and Adolescents. Current Problems in Pediatric and Adolescent Health Care, 39(5), 117143. doi:10.1016/j.cppeds.2009.02.001

Murad, M. H., Elamin, M. B., Garcia, M. Z., Mullan, R. J., Murad, A., Erwin, P. J., \& Montori, V. M. (2010). Hormonal therapy and sex reassignment: a systematic review and meta-analysis of quality of life and psychosocial outcomes. Clinical Endocrinology, 72(2), 214-231. doi:10.1111/j.1365-2265.2009.03625.x

Murshak, J. (2017) TRANScending the Medical Model: A Phenomenological Study of Trans People, Language, and Suffering (Bachelor's thesis, Kalamazoo College). Retrieved from https://www.academia.edu/38733466/

Olson-Kennedy, J., Okonta, V., Clark, L. F., \& Belzer, M. (2018). Physiologic Response to Gender-Affirming Hormones Among Transgender Youth. Journal of Adolescent Health, 62(4), 397-401. doi:10.1016/j.jadohealth.2017.08.005।

Passos, T. S., Teixeira, M. S., \& Almeida-Santos, M. A. (2019). Quality of Life After Gender Affirmation Surgery: A Systematic Review and Network Meta-analysis. Sexuality Research and Social Policy. doi:10.1007/s13178-019-00394-0

Rehman, J., Lazer, S., Benet, A. E., Schaefer, L. C., \& Melman, A. (1999). The reported sex and surgery satisfactions of 28 postoperative male-to-female transsexual patients. Archives of sexual behavior, 28(1), 71-89.

Sabra, J. J., Fang, C. X., \& Kundu, R. V. (2018). A Knowledge-Based Assessment of Dermatological Care for Transgender Women. Transgender Health, 3(1), 71-

73. doi:10.1089/trgh.2018.0001 


\section{2nd World Conference on Teaching and Education}

Sloan, C. A., \& Berke, D. S. (2018). Dialectical behavior therapy as a treatment option for complex cases of gender dysphoria. In M. R. Kauth \& J. C. Shipherd (Eds.), Adult transgender care: An interdisciplinary approach for training mental health professionals (pp. 123-139). New York, NY, US: Routledge/Taylor \& Francis Group

Spiegel, J. H. (2008). Challenges in Care of the Transgender Patient Seeking Facial Feminization Surgery. Facial Plastic Surgery Clinics of North America, 16(2), 233238. doi:10.1016/j.fsc.2007.11.011

Viner, R. M., Brain, C., Carmichael, P. (2005) Sex on the brain: dilemmas in the endocrine management of children and adolescents with gender identity disorder. Archivers of Disease in Childhood, 90.

Wang, Y. (2019). A Proposed Approach Treating Gender Dysphoria Through Body Image Therapy (Thesis). College of William and Mary, Williamsburg, Virginia. doi: 10.31234/osf.io/7yt65

White Hughto, J. M., \& Reisner, S. L. (2016). A Systematic Review of the Effects of Hormone Therapy on Psychological Functioning and Quality of Life in Transgender Individuals. Transgender Health, 1(1), 21-31. doi:10.1089/trgh.2015.0008

Wilczynski, C., \& Emanuele, M. A. (2014). Treating a Transgender Patient: Overview of the Guidelines. Postgraduate Medicine, 126(7), 121-128. doi:10.3810/pgm.2014.11.2840

World Professional Association for Transgender Health. (2011). Standards of care for the health of transsexual, transgender, and gender nonconforming people. World Professional Association for Transgender Health.

Wylie, K., Knudson, G., Khan, S. I., Bonierbale, M., Watanyusakul, S., \& Baral, S. (2016). Serving transgender people: clinical care considerations and service delivery models in transgender health. The Lancet, 388(10042), 401-411. doi:10.1016/s0140-6736(16)006826

Zeeman, L., Aranda, K., Sherriff, N., \& Cocking, C. (2017). Promoting resilience and emotional well-being of transgender young people: research at the intersections of gender and sexuality. Journal of Youth Studies, 20(3), 382-397. doi:10.1080/13676261.2016.1232481

Zucker, K. J. (2019). Adolescents with Gender Dysphoria: Reflections on Some Contemporary Clinical and Research Issues. Archives of Sexual

Behavior. doi:10.1007/s10508-019-01518-8

Zucker, K. J., Bradley, S. J., Owen-Anderson, A., Kibblewhite, S. J., \& Cantor, J. M. (2008). Is Gender Identity Disorder in Adolescents Coming out of the Closet? Journal of Sex \& Marital Therapy, 34(4), 287-290. doi:10.1080/00926230802096192

Zucker, K. J., Bradley, S. J., Owen-Anderson, A., Singh, D., Blanchard, R., \& Bain, J. (2011). Puberty-Blocking Hormonal Therapy for Adolescents with Gender Identity Disorder: A Descriptive Clinical Study. Journal of Gay \& Lesbian Mental Health, 15(1), 5882. doi:10.1080/19359705.2011.530574 